\title{
Management of a Giant Ovarian Cyst by Keyless Abdominal Rope-Lifting Surgery (KARS)
}

\section{Dev bir Over Kistinin Keyless Abdominal Rope-Lifting Surgery (KARS) ile Sağaltımı}

\author{
Kahraman Ülker1, Mustafa Ersöz', Ürfettin Hüseyinoğlu² \\ ${ }^{1}$ Kafkeas University School of Medicine, Department of Obstetrics and Gynecology, Kars, Turkey, ${ }^{2}$ Kafkeas University School of Medicine, \\ Department of Anesthesia and Reanimation, Kars, Turkey
}

\begin{abstract}
Ovarian cysts over 5 and $15 \mathrm{~cm}$ in diameter are described as large and giant, respectively. In addition, women having large cysts without regression in 6-8 weeks time are candidates for surgery. Although data has been published on laparoscopic or laparoscopy assisted management of large and giant cysts, midline laparotomy is still preferred by many surgeons, particularly in cases of giant cysts. In this paper, we present the management of a $20 \mathrm{~cm}$ serous ovarian cyst by a single-incision, transumbilical, gasless laparoscopic approach.
\end{abstract}

Key words: giant ovarian cyst, laparoscopy assisted, minimally invasive surgery, serous cystadenoma, KARS

\section{ÖZET}

Over kistleri; 5 ve $15 \mathrm{~cm}$ üzerinde çapları olduğunda sırasıyla büyük ve dev olarak tanımlanırlar. 6-8 haftada gerilemeyen büyük kisti olan kadınlar cerrahi sağaltıma adaydırlar. Büyük ve dev kistlerin laparoskopi ya da laparoskopi yardımlı mini-laparotomi ile sağaltımı yayınlanmıș pek çok veri olmasına rağmen özellikle dev kistlerde laparotomi halen birçok cerrah tarafından tercih edilmektedir. Bu yazıda, $20 \mathrm{~cm}$ 'lik seröz over kistinin trans-umbilikal, tek insizyondan, gazsız laparoskopik yaklașımla sağaltımını sunuyoruz.

Anahtar kelimeler: dev over kisti, laparoskopi yardımlı, minimal invazif cerrahi, seröz kistadenom, KARS

Minimally invasive surgery has been widely accepted as the standard management option in cases where an adnexal mass is expected to be benign preoperatively. However, it does come with some limitations in terms of visualization and manipulation due to the large volume of the cyst. Further disadvantages of this technique are the rupturing and spilling of cyst contents into the peritoneal cavity and unexpected malignancy.

Kahraman Ülker, Kafkas Üniversitesi Tap Fakültesi Kadnn Hastallklar ve Doğum Anabilim Dal, Kars, Türkìye,

Tel.05055700574Email.kahramanulker@hotmail.com

Gelis Taribi: 15.05.2011 • Kabul Taribi: 12.06.2011
Ovarian cyst is the fourth most common indication for gynaecological admission in the United States with $5-10 \%$ of women anticipated to undergo a surgical procedure for a suspected ovarian neoplasm during their whole life time $e^{1,2}$.

Ovarian cysts over 5 and $15 \mathrm{~cm}$ in diameter are described as large and giant, respectively ${ }^{3}$. In addition, women having large cysts without regression in 6-8 weeks time are candidates for surgery. Although data has been published on laparoscopic or laparoscopy assisted management of large and giant cysts, midline laparotomy is still preferred by many surgeons, particularly in cases of giant cysts.

In this paper, we aim to present the management of a $20 \mathrm{~cm}$ serous ovarian cyst by a single-incision, trans-umbilical, gasless laparoscopic approach: keyless abdominal rope-lifting surgery (KARS).

\section{Case}

A 22 year-old, unmarried female with the symptoms of abdominal pain, fullness, distension and bulging was referred to our Obstetrics and Gynecology department. She had been experiencing these disturbing symptoms for two days prior to referral. The day before admission to our department, she had presented herself to the maternity hospital and had been referred to our hospital for the management of a giant ovarian cyst by a minimal invasive approach.

Upon physical examination, we observed a $20 \mathrm{~cm}$ bulging, tender mass in the abdominal cavity (Figure 1). The mass was covering the whole space between the pubic bone and the umbilicus. The upper border of the mass was at $1-2 \mathrm{~cm}$ above the umbilicus. Palpation revealed what seemed to be a semi-solid mass. 


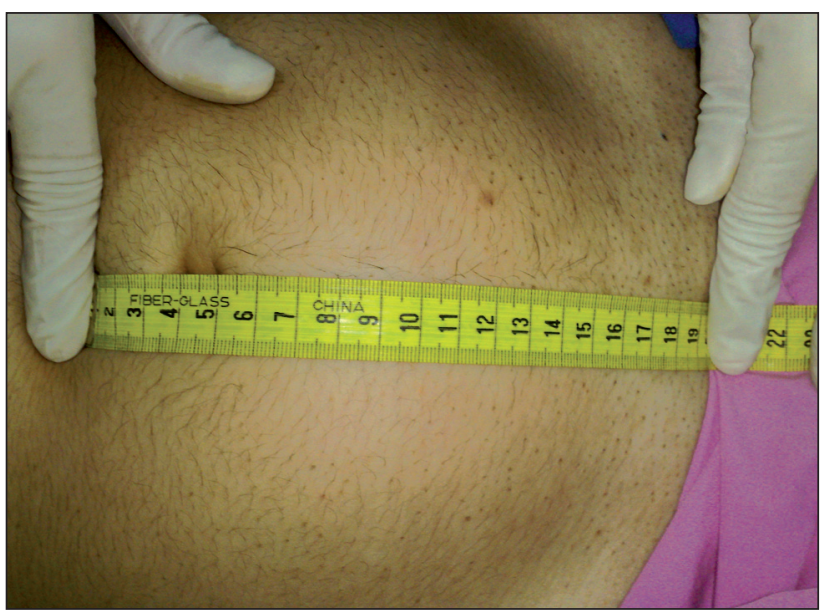

Figure 1. The $20 \mathrm{~cm}$ ovarian cyst was bulging outside the abdominal cavity

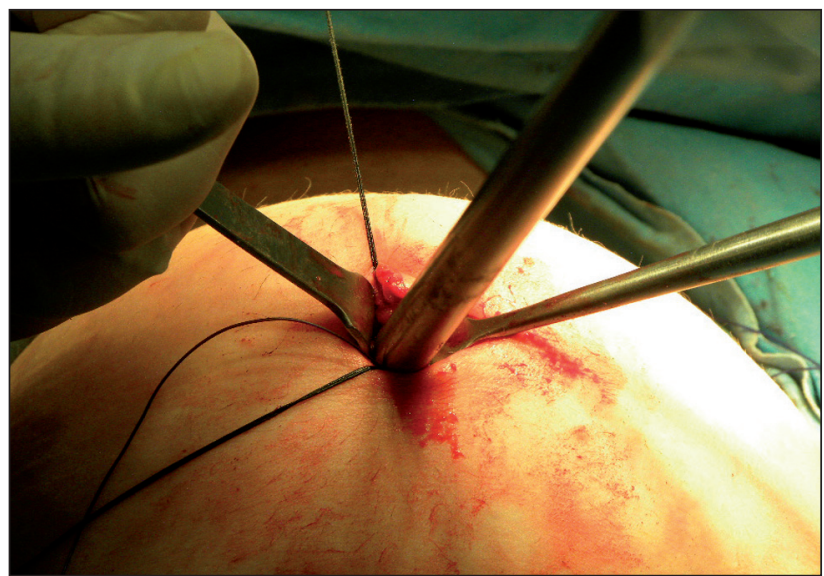

Figure 3. Two intra facial stitches at 6 and 12 o'clock positions to lift the entry site. The telescope was inserted to explore the abdominal cavity for adhesions or injuries.

During the ultrasound examination, we diagnosed a cystic mass with the dimensions of $87.66 \times 168.86 \times 198.22 \mathrm{~mm}$. There was an opaque lesion with diameters of $20 \times 26 \mathrm{~mm}$ in the lower anterior segment of the cyst. There was no sign of calcification, papillary protrusion, or septation of the cyst, nor was it multiloculated. In addition, the margins of the cyst wall were smooth and thin. Doppler ultrasound study of the ovarian and the cyst vessels revealed no increase in vascularisation. Laboratory studies of tumour markers including CA 125 and magnetic resonance imaging findings supported the benign nature of the cystic mass.

Assuming the cyst as benign in nature, we planned surgery to extirpate the cyst. Because the patient was concerned about both her future fertility and there

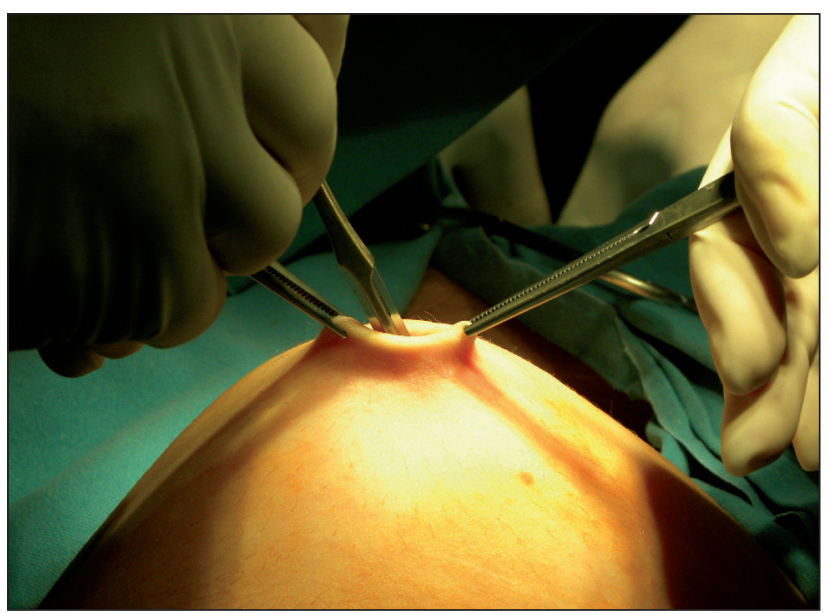

Figure 2. The intra-umbilical $1,5 \mathrm{~cm}$ incision to create the abdominal access pathway

being a wound scar in the operative field, we planned to perform surgery by a technique which allowed us to preserve the ovary and the cosmesis.

The patient was prepared for surgery under general anesthesia. After lifting the umbilical fold with 2 clamps bilaterally, a $1.5-2 \mathrm{~cm}$ transverse incision was performed at the centre of the umbilicus (Figure 2). Following incision of the skin, the subcutaneous tissue was dissected bluntly with the tip of a fine instrument, similar in appearance to a Kelly clamp. The fascia was fixed within the jaws of two strong but fine instruments. Following the fine and careful dissection of the facial layer with a fine dissection scissor, the access route into the abdominal cavity was constructed.

The inner side of the abdominal wall surrounding the entry site was examined for probable adhesions by inserting the index finger. Two separate stitches at 6 and 12 o'clock positions were placed into the facial layer underlying the incision by using a \# 0 delayedabsorbable suture. With the aid of these stitches, the entry site was elevated and a telescope was gently and slowly introduced into the incision to search for any possible injury or adhesion (Figure 3).

The needle of the Verress cannula was taken off and one tip of a \#1 nylon suture was inserted approximately $8-10 \mathrm{~cm}$ into the Verress cannula (Figure 4). The loaded cannula was introduced into the elevated entry site under direct and telescopic vision. At a level of $5 \mathrm{~cm}$ below the entry, the cannula was oriented laterally $6-7 \mathrm{~cm}$ to the right side to avoid injury to the epigastric vessels. By using the sharp tip of the 


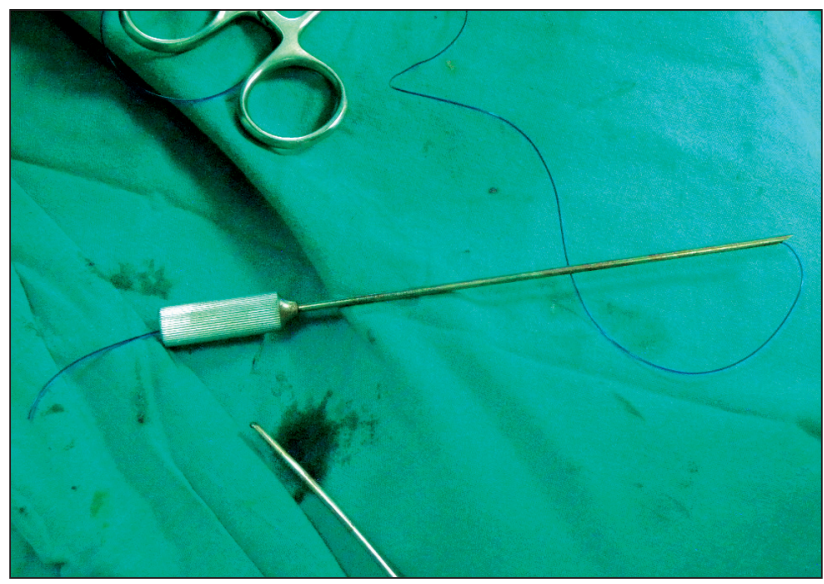

Figure 4. Preparation of the Verress cannula. A nylon suture was inserted into the cannula of the Verress needle.

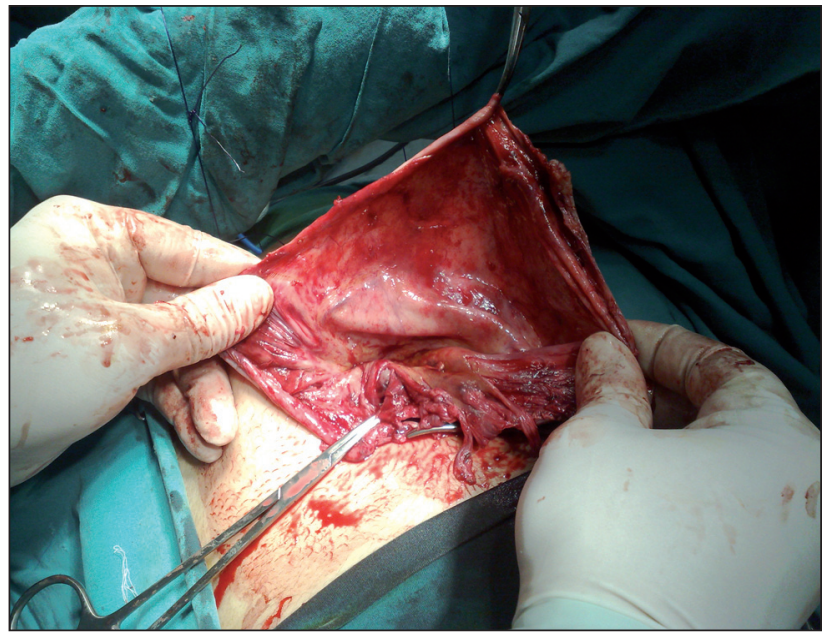

Figure 6. The cyst capsule was extirpated as in open, conventional surgery.

cannula, the abdominal wall was pierced from inside towards outside and the suture was unloaded outside the abdominal wall. The unloaded cannula was then taken back from the entry and the second tip of the suture was loaded into the cannula. At a level of 10 $\mathrm{cm}$ below the entry, the cannula was oriented laterally and the abdominal wall was pierced from inside towards outside at level of $5 \mathrm{~cm}$ below the first tip's passage. The same procedure was repeated symmetrically on the left side of the abdominal wall. The abdominal wall was elevated by an assistant and the two sutures were tied separately over a sterilized and draped universal ether screen placed at the centre of the line between the umbilicus and the pubic bone (Figure 5). The aim was to provide a $10 \mathrm{~cm}$ elevation of the abdominal wall.

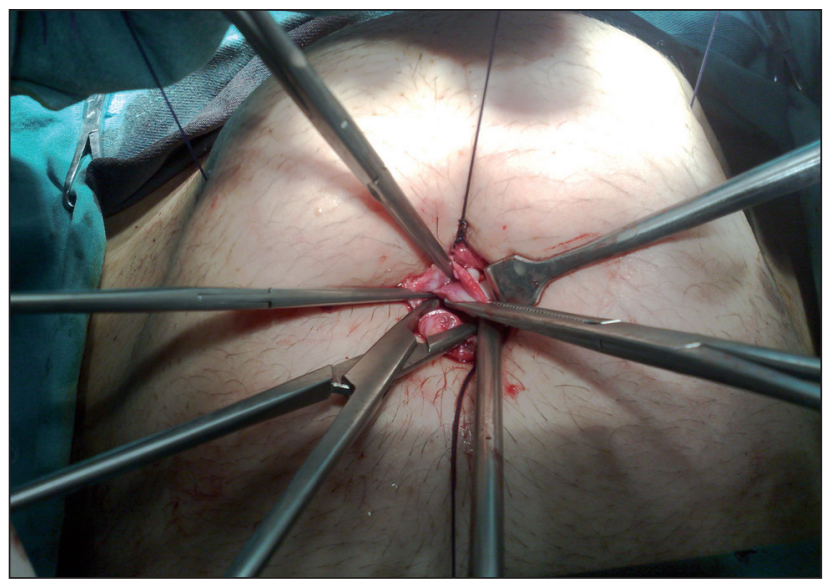

Figure 5. The abdominal wall was lifted with two ropes (suture) penetrating all layers of the abdominal wall. The sutures were tied on a pre-prepared sterilecovered ether screen. The cyst was aspirated and brought outside the abdominal cavity with laparoscopic and conventional surgical hand instruments.

Following the completion of the abdominal lifting process, the cyst was punctured under telescopic view with the tip of the hook by using mono-polar energy, and the contents of the cyst were aspirated by the aspiration device inserted into the cystic cavity. The flat cystic wall was carried out of the abdominal cavity through the umbilical opening with laparoscopic hand instruments (Figure 5). The capsule of the cyst was extirpated as it would be in open surgery (Figure 6). Following pin-point coagulation of the bleeding vessels, the edges of the cyst wall was enclosed by three stitches in order to prevent hematoma formation. The left ovary and the Fallopian tube were replaced in their original positions and the lifting ropes were cut and removed. Following the removal of the umbilical sutures, the umbilical entry side was closed with delayed-absorbable sutures. The covering skin of the umbilical region was closed subcutaneously (Figure 7).

One day later the patient was discharged with a prescribed analgesic. The pathologic diagnosis was a serous cyst.

\section{Discussion}

Ovarian masses, cystic or solid, are generally managed by laparotomy with a full midline incision ${ }^{4-6}$, followed by a cystectomy and/or oophorectomy. However, the mid-line vertical laparotomy and the resulting loss of an ovary from this procedure cause both a visible vertical scar and diminish the patient's fertility capacity. These aspects of treatment are 


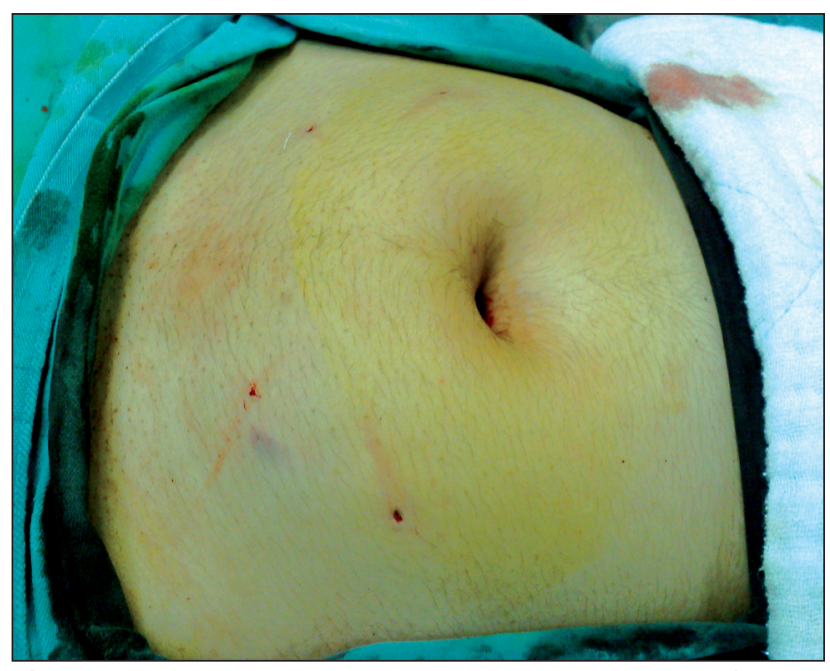

Figure 7. Post-operatively the incision was hidden into the umbilical fold. Note the traces of the sutures which had disappeared 10 days later.

unacceptable for many younger and nulliparous patients. Minimal access surgery, which includes minilaparotomy, laparoscopy and laparoscopy assisted mini-laparotomy, has cosmetic priority. Furthermore, there are various adjunct techniques incorporated into the minimal access surgery to improve the success and outcome of the surgery. Ultrasound-guided cyst aspiration, pre or intra-operative aspiration using a needle or a supra-pubic catheter, drainage and aspiration in an endobag, drainage through the vagina following hysterectomy or through a posterior colpotomy are among the techniques which have been previously published ${ }^{7-14}$.

In our patient, because of her young age and the desire for future pregnancy, an approach that considers both cosmetics and fertility had to be chosen. Intraumbilical entry was the only site that may have interfered with cosmetic solicitude. To counter this, the skin incision was buried and hidden in the umbilical fold at the end of the surgery. Traces of the lifting sutures were invisible at the $10^{\text {th }}$ postoperative day. At the second month following surgery, there was no evidence of the surgery upon inspection of the abdominal wall. The left ovary was completely preserved and the cyst capsule was completely removed.

By removing the shrunken cyst externally, it became possible and easy to remove the cyst wall completely. Moreover, complete and satisfactory haemostasis by pinpoint coagulation was much more easily managed and ovarian tissue for future fertility was also completely preserved. In laparoscopic cystectomy, haemostasis and complete removal of the cyst wall can be more difficult and, due to the difficulty of drying the bleeding tissue, more tissue is generally coagulated than is strictly required, resulting in more functional tissue lost from the ovary.

Different approaches have been described to prevent the spill of probable cancer cells ${ }^{14}$. We preferred to rupture the cyst wall by using the fine tip of the hook after elevating the cyst wall towards the abdominal entry site. In addition, the suction device was immediately inserted into the cyst wall opening. Since there was no visible spillage of the cyst contents, this method was found to be adequately safe for routine use. However, we recommend development of the cyst aspiration technique in order to be certain of its role in preventing the spilling of cyst contents.

Increased intra-abdominal pressure during CO2 laparoscopy causes a mild respiratory acidosis which can be managed by increasing the ventilation by $10-25 \%$. The mild acidosis can be tolerated well by healthy patients. However, in patients with cardio-vascular and pulmonary diseases, cardiac arrhythmias, athelectasis, and pulmonary shunts may be observed ${ }^{15}$. Although our patient was a young and healthy woman, the gasless approach was safer for our purposes. In addition, the gasless nature of the procedure enables the use of conventional surgical instruments and ends the dependency on gas preserving trocars.

\section{Conclusion}

Keyless abdominal rope-lifting surgery (KARS) is a feasible option for the management of benign natured giant ovarian cysts. According to the presented case, it is superior in terms of haemostasis, cosmesis and fertility preservation when compared with conventional laparoscopy. However, to reach a more accurate final conclusion prospective controlled trials are needed.

\section{References}

1. Eltabbakh GH. Laparoscopic management of ovarian cysts. Contemporary Ob/Gyn 2003; 48:37-50.

2. DiSaia PJ, Creasman WT, editors. The adnexal mass and early ovarian cancer. In: Clinical Gynecologic Oncology. $5^{\text {th }}$ ed. St.Louis, Missouri: Mosby Press; 1997 : 253-79.

3. Dolan MS. Boulanger SC. Salameh JR. Laparoscopic Management of Giant Ovarian Cyst. JSLS 2006; 10:254-6. 
4. Baysal B, Gürateş B, Mutafoğlu T, et al. Coexistence of a Huge Ovarian Mucinous Cystadenoma and Mature Cystic Teratoma. T Klin J Gynecol Obst 1996; 6: 277-8.

5. Sujatha VV, Babu SC. Giant ovarian serous cystadenoma in a postmenopausal woman: a case report. Cases Journal 2009; 2:7875.

6. Mülayim B, Gürakan H, Dağlı V, et al. Unaware of a giant serous cyst adenoma: a case report. Arch Gynecol Obstet 2006; 273: 381-83.

7. Leng J, Lang J, Zhang J, et al. Role of laparoscopy in the diagnosis and treatment of adnexal masses. Chin Med J 2006; 119:202-6.

8. Mecke H, Savvas V. Laparoscopic surgery of dermoid cystsintraoperative spillage and complications. Eur J Obstet Gynecol Reprod Biol 2001; 96:80-4.

9. Ma KK, Tsui PZY, Wong WC, et al. Laparoscopic management of large ovarian cysts: more than cosmetic considerations. Hong Kong Med J 2004; 10:139-41.

10. Ceyhan T, Atay V, Güngör S, et al. Efficacy of laparoscopicallyassisted extracorporeal cystectomy in patients with ovarian endometrioma. J Minim Invasive Gynecol 2006; 13:145-9.

11. Göçmen A, Atak T, Uçar M, et al. Laparoscopy-assisted cystectomy for large adnexal cysts. Arch Gynecol Obstet 2009; 279:17-22.

12. Cocciaa ME, Rizzelloa F, Braccob GL, et al. Seven-liter ovarian cyst in an adolescent treated by minimal access surgery: laparoscopy and open cystectomy J Pediatr Surg 2009; 44: E58.

13. Ateş O, Karakaya E, Hakgüder G, et al. Laparoscopic excision of a giant ovarian cyst after ultrasound-guided drainage. J Pediatr Surg 2006; 41: E9-11.

14. Pelosi MA II, Pelosi MA III. A novel minilaparotomy approach for large ovarian cysts OBG Management 2004;16(2)

15. Carry PY, Gallet D, François Y, et al. Respiratory mechanics during laparoscopic cholecystectomy: the effects of the abdominal wall lift. Anesth Analg 1998; 87:1393-7. 